\title{
$\mathrm{BaTiO}_{3}$ 自立薄膜におけるクラック密度の低減と 配向性の成長基板温度依存性*
}

\author{
出口＼cjkstart恭平*1 · 木下健太郎 $* 1, * 2 \cdot$ 吉田大一郎*1,*3 \\ 花田 明紘 $* 1 \cdot$ 岸田＼cjkstart悟*1,*2
}

\section{Reduction in the Density of Cracks and the Substrate Temperature Dependence of Orientation in the Freestanding $\mathrm{BaTiO}_{3}$ Thin Films}

\author{
Kyohei DEGUCHI*1, Kentaro KINOSHITA*1,*2, Dai-ichiro YOSHIDA*1,*3, \\ Akihiro HANADA ${ }^{* 1}$ and Satoru KISHIDA $* 1, * 2$

\begin{abstract}
${ }^{* 1}$ Department of Electrical and Electric Engineering, Tottori University, 4-101, Koyama-Minami, Tottori 680-8552, Japan *2Tottori University Electronic Display Research Center, 2-522-2, Koyama-Kita, Tottori, Tottori, 680-0941, Japan
\end{abstract} \\ *3Tottori Institute of Industrial Technology, 7-1-1, Wakabadai-Minami, Tottori, Tottori 689-1112, Japan
}

(Received October 30, 2009, Accepted April 26, 2010)

\begin{abstract}
Freestanding $\mathrm{BaTiO}_{3}(\mathrm{BTO}) / \mathrm{Pt}$ films were fabricated and the orientation and crack density of BTO films were investigated as a function of substrate temperature, $T_{\text {sub }}$, during BTO deposition. When $T_{\text {sub }}$ is low, the BTO film exhibits preferentially (101)-orientated structure. On the other hand, (001)-orientation becomes dominant when $T_{\text {sub }}$ is high. This means that controlling of orientation by changing the $T_{\text {sub }}$ is possible. In addition, the density of cracks of the BTO film on the Pt foil was lower than on the Pt $/ \mathrm{Ti} / \mathrm{SiO}{ }_{2} / \mathrm{Si} \mathrm{sub}$ strate, as a result of the removal of clamping effect of the substrate.
\end{abstract}

\section{1. はじめに}

強誘電材料はその特性から MEMS ( Micro Electro Mechanical Systems) や強誘電体メモリー等に応用されてい る1-5). 代表的な強誘電体材料として $\mathrm{Pb}(\mathrm{Zr}, \mathrm{Ti}) \mathrm{O}_{3}(\mathrm{PZT})$ があるが，PZT は構成元素に有毒な $\mathrm{Pb}$ を含んでいる. $\mathrm{Pb}$ は近年欧州の特定有害物質制限（RoHS）をはじめ, 国際的 に規制の対象とされている．PZT は十分な代替材料が未開 発のため, 現状では特例として規制の対象外であるが，代替 材料の開発が急がれる. そこで, 我々は PZTの代替材料と して $\mathrm{Pb}$ を含まず同じペロブスカイト構造を持つ $\mathrm{BaTiO}_{3}$ （BTO）に着目した. 強誘電体デバイスの作製には，その用 途に応じて強誘電体の配向性を制御する必要がある.

一方, 強誘電体薄膜は下地基板による拘束 (クランプ効果) のため, 本来得られるはずの電気特性が低下することや基板 と膜間で熱膨張係数の違いによって膜に亀裂が生じやすくな ることが知られている6,7). Lee 等は下地に基板から自立し た Pt 箔を用い，その上に $\mathrm{PZT}$ を堆積した $\mathrm{PZT} / \mathrm{Pt}$ 自立膜 が，クランプ効果からの解放によって優れた機械結合係数を 有することを報告した ${ }^{8)}$. 更に, $\mathrm{PZT} / \mathrm{Pt}$ 自立膜では亀裂の 減少も確認されている。しかし，BTO 薄膜の自立化に関す る報告は未だない。

* 平成 21 年 11 月 5 日 第50回真空に関する連合講演会で発表

*1 鳥取大学工学研究科電気電子工学専攻 ( 取市湖山町南 4-101)

*2 鳥取大学工学部付属電子ディスプレイセンター（伃680-0941 鳥取県鳥取市湖山町北 2 丁目 522 番地 2 セコム山陰 IT ラボラ トリー内 $2 \mathrm{~F}$ )

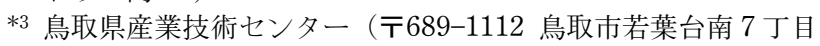
1-1)
本研究は BTO $/ \mathrm{Pt}$ 自立膜における BTO の配向制御と自立 膜による膜質の向上を目的とし，BTOをスパッタ成膜する 時の基板温度 $T_{\mathrm{sub}}$ が BTO の配向性に及ぼす影響とクランプ 効果からの解放が膜に及ぼす影響について調查した。

\section{2. 実験方法}

\section{$2.1 \mathrm{Pt}$ 箔の作製}

Fig. 1 に BTO/Pt 自立膜の作製手順を示す。まず， $\mathrm{MgO}$ 基板上に真空蒸着法により $\mathrm{C}$ 層を堆積させる. その上に DC スパッタリング法により $\mathrm{Pt}$ 層を $500 \mathrm{~nm}$ 堆積させる。得ら れた $\mathrm{Pt} / \mathrm{C} / \mathrm{MgO}$ 基板を $400^{\circ} \mathrm{C}$ 酸素䨌囲気中で $1 \mathrm{~h}$ アニール 処理することで $\mathrm{C}$ 層を酸素と反応させて取り除き, $\mathrm{MgO}$ 基 板から Pt 䈃を剥離することで自立 $\mathrm{Pt}$ 䈃を得た。

\subsection{BTO 薄膜の堆積}

Table 1 にBTO 薄膜作製条件を示す，RFマグネトロン スパッタ法により $\mathrm{Pt}$ 箔 $(500 \mathrm{~nm})$ 及び $\mathrm{Pt}(100 \mathrm{~nm}) / \mathrm{Ti}$ $(20 \mathrm{~nm}) / \mathrm{SiO}_{2}(100 \mathrm{~nm}) / \mathrm{Si}(650 \mu \mathrm{m})[\mathrm{Pt}$ 基板 $]$ 上に BTO を成膜した。 モル比が $\mathrm{Ba}: \mathrm{Ti}=1: 1$ となるように計量混合 し, プレス機で直径 $75 \mathrm{~mm}$, 厚さ $7 \mathrm{~mm}$ のペレット状に成 形したものを大気中 $1150^{\circ} \mathrm{C} て ゙ ~ 4 \mathrm{~h}$ 焼成した焼結体ターゲット を用いた. スパッタ時のガス圧を $1.3 \mathrm{~Pa}$ (10 mTorr), Ar100 $\%, \mathrm{RF}$ 出力を $100 \mathrm{~W}$, 膜厚を $500 \mathrm{~nm}$ にそれぞれ固定し, $T_{\text {sub }}$ を $25^{\circ} \mathrm{C}$ から $500^{\circ} \mathrm{C}$ の間で変化させて BTO を堆積した. 成膜後, $1 \mathrm{~atm}$ の大気中で $700^{\circ} \mathrm{C}, 15$ 分間のポストアニール処 理を行った。

得られた薄膜の配向性および結晶性をX 線回折で, 表面 形態をSEM で評価した。 
MgO substrate

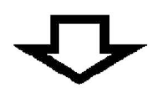

(2)

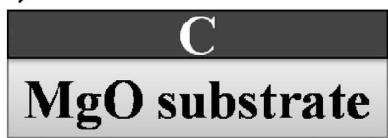

\section{$C$ coating by vacuum deposition on $\mathrm{MgO}$ substrate.}

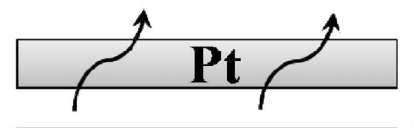

MgO substrate

$\Psi_{(5)}$

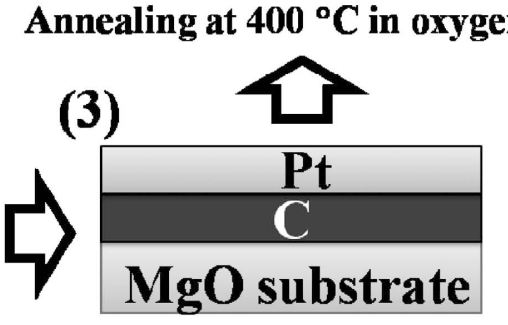

Pt coating by DC sputtering, $500 \mathrm{~nm}$ thickness Pt.

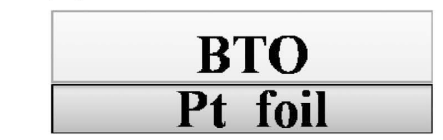

Deposition of BTO on the Pt removed from $\mathrm{MgO}$ substrate.

Fig. 1 Schematic diagram showing the procedure of fabricating the freestanding BTO film.

Table 1 BTO films prepared at experiment condition.

\begin{tabular}{c|c}
\hline \hline Substrate & $\mathrm{Pt}$ foil, $\mathrm{Pt} / \mathrm{Ti} / \mathrm{SiO}_{2} / \mathrm{Si}$ \\
\hline Substrate temperature & $25^{\circ} \mathrm{C} \sim 500^{\circ} \mathrm{C}$ \\
\hline Sputtering gas & $\mathrm{Ar}$ \\
\hline Gas pressure & $1.3 \mathrm{~Pa}(10 \mathrm{~m}$ Torr $)$ \\
\hline Film thickness & $500 \mathrm{~nm}$ \\
\hline RF power & $100 \mathrm{~W}$ \\
\hline Substrate configuration & on-axis \\
\hline Substtate-target distance & $3 \mathrm{~cm}$ \\
\hline Target composition & $\mathrm{Ba}: \mathrm{Ti}=1: 1$ \\
\hline Annealing condition & $\mathrm{O}_{2} 1 \mathrm{~atm}, 700^{\circ} \mathrm{C}, 15 \mathrm{~min}$ \\
\hline
\end{tabular}

\section{3. 結果及び考察}

Fig. 2 の実線と点線で表されたデータは，それぞれ自立 $\mathrm{Pt}$ 䈃と $\mathrm{Pt}$ 基板の XRD パターンを示す。何れの膜において も Pt 起因のピークが観測された. 更に, $\mathrm{Pt}(111)$ のピーク 位置が $\mathrm{Pt}$ 基板で $39.45^{\circ} \mathrm{C}$ ，自立 $\mathrm{Pt}$ 筞では $39.8^{\circ}$ とずれている ことが分かる。これは，Ptを基板から剥離させることによ って基板からのストレスが解放されたことによると考えられ る. Fig. 3 にBTO $(001)$ のピーク強度 I(001) と BTO (101) のピーク強度 I (101)の和に対する I (001)の比, I (001)/ $\{\mathrm{I}(001)+\mathrm{I}(101)\}$ の基板温度依存性を示す. Pt 基板上に堆 積させた BTO (三角) と自立 Pt 箔上に堆積させたそれ（丸） は, ともに $T_{\mathrm{sub}}$ を上昇させることで $\mathrm{BTO}(001)$ 配向が支配 的となった。

Fig. 4 に $\mathrm{Pt}$ 基板及び Pt 筞上に堆積した各基板温度にお ける BTO 薄膜の表面 SEM 像を示す. Pt 基板上の BTO で は基板温度が $25^{\circ} \mathrm{C}$ (Fig. 4 (a)) から $300^{\circ} \mathrm{C}$ (Fig. 4 (b)) に上 昇することで亀裂密度の増加が観測された. 一方, Pt 䇴上 の BTO では $25^{\circ} \mathrm{C}$ 成長 (Fig. 4 (c) ), $300^{\circ} \mathrm{C}$ 成長 (Fig. 4 (d))

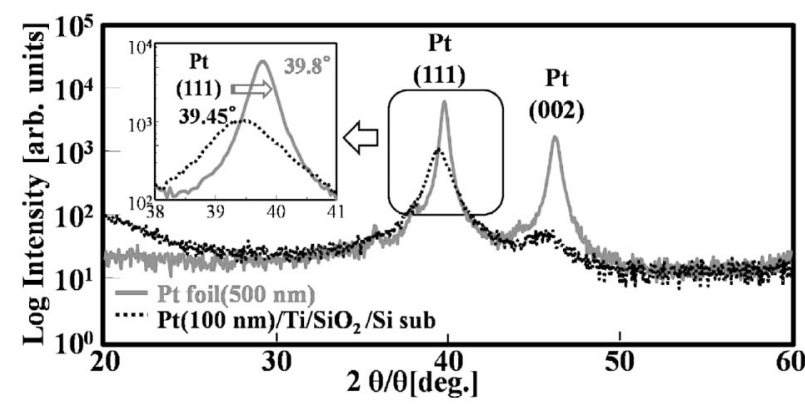

Fig. 2 X-ray diffraction patterns of Pt foil (solid line) and Pt/ $\mathrm{Ti} / \mathrm{SiO}_{2} / \mathrm{Si}$ (dotted line).

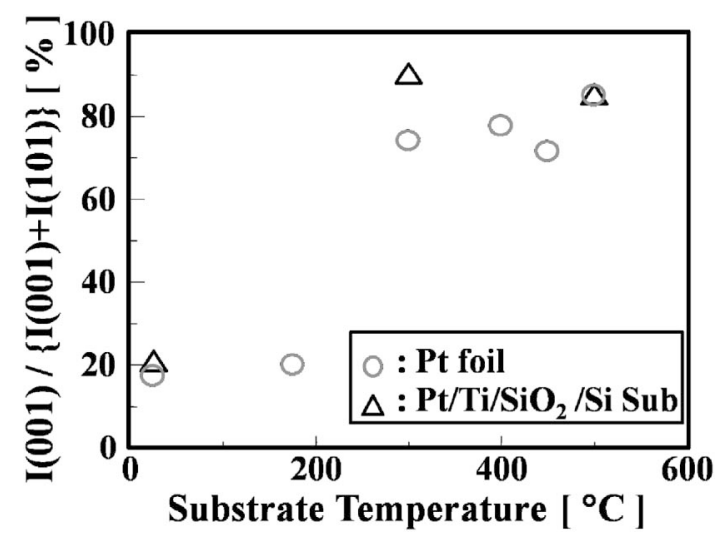

Fig. 3 The substrate temperature dependence of $\mathrm{I}(001) /$ $\{\mathrm{I}(001)+\mathrm{I}(101)\}$ of BTO on the Pt foil (triangles) and the $\mathrm{Pt} / \mathrm{Ti} / \mathrm{SiO}_{2} / \mathrm{Si}$ substrate (circles). Here, I(001) and I(101) mean intensities of (001) and (101) peaks in X-ray diffraction patterns of BTO, respectively.

ともに亀裂は観測されなかった. $\mathrm{Si}, \mathrm{SiO}_{2}, \mathrm{Ti}, \mathrm{Pt}, \mathrm{BTO}$ の熱 膨張係数はそれぞれ $2.4 \times 10^{-5} / \mathrm{K}, 0.5 \times 10^{-6} / \mathrm{K}, 8.6 \times 10^{-6} /$ $\mathrm{K}, 8.8 \times 10^{-6} / \mathrm{K}, 9.6 \times 10^{-6} / \mathrm{K}$ である. 故に $\mathrm{Si}$ の熱膨張係数

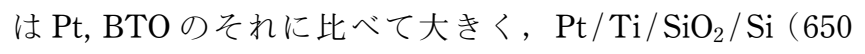




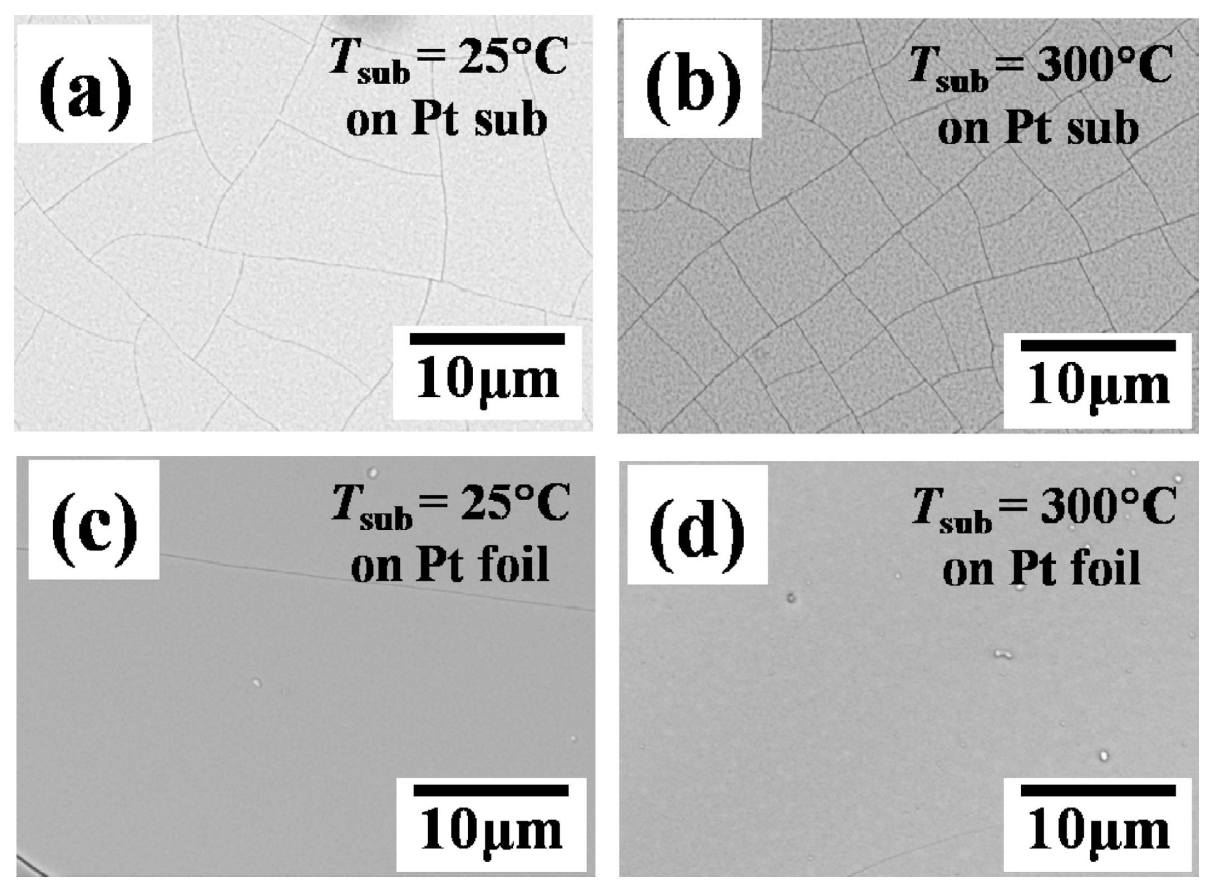

Fig. 4 SEM images of the surface of BTO films deposited (a) on $\mathrm{Pt} / \mathrm{Ti} / \mathrm{SiO}_{2}$ (Pt sub.) at $T_{\text {sub }}=25^{\circ} \mathrm{C}$, (b) on $\mathrm{Pt}$ sub. at $T_{\text {sub }}=300^{\circ} \mathrm{C}$, (c) on Pt foil at $T_{\text {sub }}=25^{\circ} \mathrm{C}$, and (d) on Pt foil $T_{\text {sub }}=300^{\circ} \mathrm{C}$.

$\mu \mathrm{m} ）$ 上の BTO に亀裂が導入される主要因となり得る. $\mathrm{BTO} / \mathrm{Pt}$ 自立膜では $\mathrm{Si}$ 基板の影響から解放されたことで亀 裂の減少が達成されたと考えられる。

\section{4. 結 論}

$\mathrm{BTO} / \mathrm{Pt}$ 自立薄膜を作製・評価したＰt 箔上においても 通常の $\mathrm{Pt}$ 基板上と同様に $T_{\text {sub }}$ によ $\mathrm{BTO}$ 薄膜の配向制御 が可能であることが示された．更に，クランプ効果からの解 放によって従来の BTO 薄膜と比べて亀裂密度が少ない薄膜 が得られた。

\section{〔文献〕}

1) T. Kobayashi, J. Tsaur and R. Maeda: Jpn. J. Appl. Phys., 44 (2005) 7078.

2) K. Tonisch, V. Cimalla, Ch. Foerster, H. Romanus, O. Ambacher and D. Dontsov: Sens. Actuat. A, 132 (2006) 658.

3) J. Lu, T. Ikehara, Y. Zhang, T. Mihara, T. Itoh and R. Maeda: Microelectron. Eng., 86 (2009) 1208.

4) R. Herdier, M. Detalle, D. Jenkins, C. Soyer and D. Remiens: Sens. Actuators A, 148 (2008) 122.

5) W. S. Lee and S. S. Lee: Sens. Actuators A, 144 (2008) 367.

6) D. Royer and V. Kmetik: Electron. Letts, 28 (1992) 1828.

7) A. L. Kholkin, Ch. Wütchrich, D. V. Taylor and N. Setter: Rev. Sci. Instrum, 67 (1966) 1935.

8) Jae-Wung Lee, Chee-Sung Park, Ji-Hoon Jo and Hyoun-Ee Kim: Appl. Phys. Lett., 91 (2007) 072903. 